\title{
Determinants of knowledge, attitudes, and practices of front-line health workers during the first wave of COVID-19 in Africa: a multi-center online cross- sectional study
}

\section{Larrey Kasereka Kamabu ( $\square$ kamabularry@gmail.com )}

1 Faculty of Medicine, Université Catholique du Graben, Butembo

Hervé Monka Lekuya

2 Department of Surgery, School of Medicine, Makerere University

Richard Newton Iranya

2 Department of Surgery, School of Medicine, Makerere University

Bienvenu Muhindo Kasusula

3 Department of Internal Medicine, Matanda Teaching Hospital,

Franck Katembo Sikakulya

4 Department of surgery, Kampala International University, Western campus

\section{Saviour Kicaber}

2 Department of Surgery, School of Medicine, Makerere University

\section{Moise Muhindo Valimungighe}

1 Faculty of Medicine, Université Catholique du Graben, Butembo

\section{Sifa Katungu Nganza}

1 Faculty of Medicine, Université Catholique du Graben, Butembo

\section{Eric Sadiki Butala}

6. Department of Obstetrics and Gynecology, Consolata Hospital Mathari,

\section{Zacharie Muhindo Sikiminya}

7. Department of ophthalmology, Kinshasa Teaching Hospital, Université de Kinshasa.

\section{Louange Maha Kathaka}

1 Faculty of Medicine, Université Catholique du Graben, Butembo

Dalton Kambale Munyambalu

4 Department of surgery, Kampala International University, Western campus

\section{Agnès Kavira Katsioto}

1 Faculty of Medicine, Université Catholique du Graben, Butembo

\section{Thérèse Yenyi Ahuka Longombe}

9 Department of Anesthesia and Critical Care, School of Medicine, University of Cheikh Anta Diop de Dakar,

\section{Bienfait Mumbere}


4 Department of surgery, Kampala International University, Western campus

\section{Adelard Kalima Nzanzu}

1 Faculty of Medicine, Université Catholique du Graben, Butembo

\section{Frederic Kavughe}

11. Department of Education and psychology, Faculty of Education and Psychology, Adventist University of Lukanga, Lukanga,

\section{Thaddée Katembo Kambere}

12. Department of Public health sciences, Faculty of Medicine, Adventist University of Lukanga, Lukanga,

\section{Ssebuufu Robinson}

4 Department of surgery, Kampala International University, Western campus

\section{Research Article}

Keywords: Knowledge, Attitude, Practices, COVID-19, Frontline Health caregivers, Africa, survey

Posted Date: December 14th, 2021

DOI: https://doi.org/10.21203/rs.3.rs-1164116/v1

License: (c) (1) This work is licensed under a Creative Commons Attribution 4.0 International License. Read Full License 


\section{Abstract}

Background: During its first wave of COVID-19 infection in sub-Saharan Africa, there was insufficient understanding of the pandemic among front-line health care professionals that has led to a misidentification, and mistreatment of affected patients, with a potential risk of contracting and spreading the disease. This study was carried out to determine the Knowledge, attitude, and practices (KAP) of front-line health workers (HWs) towards COVID-19 in Africa and their related factors.

Methods: This was a multi-centers online cross-sectional study conducted over a 3-months study-period using a google survey link among front lines HWs involved in the COVID-19 response in 26 African countries. Chi-square test \& logistic regression were used in the bivariate and multivariate analysis respectively to assess determinants of KAP. Statistical analysis was done using STATA version 16; all tests were two-sided with $95 \%$ confidence interval.

Results: Five hundred and seventeen $(517,96.3 \%)$ consented to participate in this study from 26 African countries; 289 (55.9\%) were male and 228 (44.1\%) female. Overall, most of HWs, 379 (73.3\%) showed poor knowledge about COVID-19 infection and preventive measures. In contrast, majority of them showed good attitude (89\%) and practice $(90.3 \%)$ towards prevention of COVID-19 infections. Knowledge varied among countries; Uganda had the greatest number of HWs with good knowledge. $(\mathrm{OR}=28.09, \mathrm{p}<0.0001)$ followed by Ghana (OR=10.92, $p=0.001)$ and DRC (OR: 4.59, $p=0.015)$. The cadre of HWs also influenced knowledge; doctors were the most knowledgeable as compared to other cadres (OR: 3.4, $p=0.005$ ). Additionally, knowledge increased with increasing HWs' education level $(p=0.011)$.

Attitude and practice were both influenced by HWs country of workplace $(p=0.05 \& p<0.0001$ respectively $)$ and their cadre $(p=0.025 \& p<0.0001$ respectively $)$.

Conclusions: Majority of the front-line HWs in the African region had an overall good attitude and practice towards COVID-19 infection and practice measures despite relatively poor Knowledge. The KAP is influenced by HWs country of workplace, their cadre and level of education.

\section{Introduction}

The emergence of Corona virus disease (COVID-19) in 2019 from Wuhan-China, and its exponential transmission to all countries in the World, including the fifty-two countries of Africa, present a delicate situation for low-resource countries. This current pandemic has shaken the entire World [1-4, 5, 6].

During its first wave, while millions of people worldwide stayed at home to minimize the transmission of the COVID-19, most healthcare workers (HWs) remained at the forefront of the response to this pandemic. They go to clinics and hospitals, exposing themselves to a high risk of COVID-19 [7]. In addition to exposure to the pathogen, long hours of work, psychological stress, fatigue, social stigma and physical abuse were some of the additional burdens faced by the HWs [8]. A recent study by Hakan E. et al., found that $300,000 \mathrm{HWs}$ from thirty-seven countries had already gotten COVID-19. In addition to the high 
number of infections, over 115,000 of HWs have already lost their lives around the World as of 22th October 22, 2021. Of the thirty-seven countries surveyed, the United States had the highest coronavirus infections among HWs with 114,500 infections (9). Mexico followed with a reported 78,200 infections while France and Italy had 30,000 and 29,000 coronavirus infections, respectively(9). While the United States had the highest number of infections, the rate of infections adjusted for the population size was highest in Mexico, Italy, and France [9].

As of $16^{\text {th }}$ October 2021 , over $242,801,421$ cases and $4,929,826$ deaths have been reported globally $(2.96$ $\%$ ). The USA is the most affected, with over $50 \%$ of cases and $60 \%$ of deaths reported in this region(10). The United States of America, with over 45 million cases of COVID-19 and over 733,000 deaths, currently constitutes the most infected country in the World [10]. Still, an overall decrease in the number of cases and deaths across the region has been reported by $11 \%$ in the last 40 days. Despite the overall decrease of cases in the region, Uganda reported an intensive community transmission in capital Kampala and an increase of over $300 \%$ of cases; and similarly, an overall increase in the case number has been reported in Namibia and Nigeria in term of $55 \%$ and $19 \%$ respectively $[11,12]$. Despite resource limitations in the African health care system, COVID-19 seems to be contained and under control. Several hypotheses have been fronted; one of them is the relatively younger population in the continent (more than $60 \%$ of the population in Africa are below the age of 25). Other factors cited include low travel and outdoor living, expertise in epidemic control from tackling other outbreaks, and cross-immunity from other coronaviruses [13].

Despite governmental efforts to mobilize HWs to support the health systems, most of those health professionals were not sufficiently educated about preventive measures of this novel disease and were at a high risk of contracting and subsequently spreading the virus to uninfected patients who seek_assessment $[6,8,14]$. A study among HWs in Henan, China, revealed that over $80 \%$ of HWs had sufficient Knowledge of COVID-19 and correct practices regarding COVID-19 [15]. In Uganda, a study done at Mulago and Kiruddu Hospitals reported $69 \%$ of HWs had good Knowledge, $21 \%$ had a positive attitude, and $74 \%$ had good practices towards COVID-19 $[14,16]$. Several studies reported that age and education level were significantly associated with good Practice and Knowledge towards COVID-19 [1618]. There is a paucity of evidence of the current KAP towards COVID-19 in sub-Saharan Africa, despite several WHO materials, up-to-date, and governments' guidelines. Understanding front-line HWs' KAP and possible risk factors help to improve the safety of both the HWs and the general population. This study aimed to assess the KAP of the front-line HWs towards COVID- 19 during the first wave of the pandemic, and also to identify determinant factors of KAP towards COVID-19 pandemic.

\section{Methods}

Study design, setting, and participants: This was a cross-sectional descriptive study using an online structured questionnaire (French and English versions), sent to the frontline HWs in several African countries via emails between April 2020 and July 2020. The frontline HWs surveyed included nurses, 
doctors and other cadres (anesthesia and laboratory personnel) in any level of practice experience and working in any level of African hospital involved in COVID-19 patient care.

Study instrument, variables and data collection: The online Google Form link was sent to frontline health care givers via emails, or social media platforms (WhatsApp, Twitter, and Facebook) with a help of a focal lead country person, and reminders were sent 3 times a week for duration of 4

months. Standardized and pre-tested screening tools and adjusted pre-validated questionnaire were used to obtain information on the study variables. Questions and answers about COVID-19 in the webpage of WHO and other previous studies [16, 23-26] were adapted to formulate the questionnaire for the interview. A pilot study was carried out on $11 \mathrm{HWs}$ from Benin, Ghana, Malawi and Niger, and adjustment were made based on their opinions relating to the feasibility of the questionnaire, and the final questionnaire was reviewed by the authors accordingly. The final questionnaire had four sections. The first section comprised of 7 questions on socio-demographic characteristics of the participants. The second section included 12 questions regarding the Knowledge of HWs on COVID-19 using two points scale. Each incorrect response weighed 0 point and 1 for correct responses. A HW who got sixty percent or more of the responses correct was categorized as having a good knowledge while the one who got less than sixty percent correct responses was categorized as having poor knowledge. The third section had 5 questions assessing attitude of HWs in a Likert scale of agreement format $[16,25]$. A HW who got sixty percent or more of the responses correct was categorized as having a good attitude while the one who got less the sixty percent, poor attitude. The fourth section included 5 questions regarding the practices of COVID- 19 . The responses were: always, occasional, never, and neutral each weighing 3, 2, and 1 point respectively for a given practice. Again, a cut of score of sixty percent or more differentiated good from poor practice. As part of quality assurance, the most active email of each participant was collected to identify duplicate responses. We used the random sampling to recruit the study participants.

Statistical analysis: Fully completed questionnaires were extracted from Google Forms and exported to a Microsoft Excel 2016 for cleaning and coding. The cleaned data was exported to STATA version 16 for analyses $[16,25]$. The means and standard deviations were used to describe continuous data, while the frequencies and proportions described categorical data. Chi-square test of independence was used in the bivariate analysis to identify potential predictors of KAP. All variables in the bivariate analysis with $\mathrm{p}$ value $<0.2$ were included in the multivariate_logistic regression model to assess determinants of KAP towards COVID-19 African frontline health workers during the first wave of COVID-19 pandemic. All analysis were two-sided with 95 percent confidence level. Results reported in crude and adjusted Odds ratio.

Ethical considerations: The protocol has been cleared by the Integrated Multidisciplinary Research Center Ethics committee (IMRCEC) of Adventist University of Lukanga (Campus Wallace, Lukanga, D.R. Congo) (Protocol Number.02/2020), and all participants provided an informed consent, and their anonymity were guaranteed.

Results 
Socio-demographic characteristic of study participants: A total of five hundred and thirty-seven (537) Health workers from 26 African countries responded to the survey. Five hundred and seventeen (517, $96.3 \%)$ consented to participate in the study. Majority of the HWs were from the Democratic republic of Congo; DRC (48\%), Uganda (11.6\%), Algeria (11.0\%), Ghana (7.2\%) and $22.24 \%$ from the other countries (See table 1). Table 2 shows the socio-demographic characteristics of the study participants. Of the 517 health care givers, 289 (55.9\%) were males and 228 (44.1\%) females. Based on HWs' cadre, 297 (57.4\%) of the HWs were doctors, $154(29.8 \%)$ nurses and the rest 66 (12.8\%) where other cadres (anaesthesia personnel, laboratory technicians etc.). In terms of education level, $64.4 \%$ of the HWs were degree holders, the least numbers were for certificate holders (2.9\%). Overall, most of the HWs showed poor knowledge about COVID-19 infection and preventive measures $(73.3 \%$ and $26.7 \%$ for poor and good knowledge respectively). In contrast, majority of them showed good attitude and practice measures towards prevention of COVID-19 infections. (89\% and $90.3 \%$ respectively).

Determinants of Knowledge of COVID-19 among healthcare givers: Generally, statistically significant determinants of knowledge of COVID-19 infection and prevention measures in the multivariate analysis were HWs' country of workplace, their cadre, and education level.

Algeria had the least number of HWs with good knowledge about COVID-19 while Uganda had the greatest number with good knowledge. $(\mathrm{OR}=34.09, \mathrm{p}<0.0001)$ followed by Ghana $(\mathrm{OR}=13.22, \mathrm{p}<$ 0.0001). HWs from DRC were also more knowledgeable on COVID-19 than those from Algeria (OR $=4.59$, $\mathrm{p}=0.015$ ). Compared to other cadres of HWs (Allied HWs), doctors were 3.26 times more knowledgeable on COVID-19 infection and preventive measures $(O R=3.26, p=0.005)$ while nurses were $36 \%$ less likely to have good knowledge of COVID-19 infection and prevention measures compared to the allied health care-givers although this difference was not statistically significant $(O R=0.64, p=0.383)$. Except for certificate holders, knowledge of COVID-19 infection and prevention measures increase with increasing level of education from diploma to master's level.

Determinants of attitudes towards COVID-19 among HWs: As shown in Table 6, differences in HWs' attitudes towards COVID-19 infection and prevention measures were statistically significant among the various countries. All study participants (HWs) from Ghana showed a good attitude towards COVID-19 infection and preventive measures. Algeria had the least number of HWs with a good attitude compared to those from Uganda (OR: 4.58, $p=0.046$ ), DRC (OR: 3.95, $p=0.013$ ), and others (OR: 2.57, $p=0.045$ ). The cadre of HWs also had a statistically significant positive influence on attitude towards COVID-19 infection and prevention measures. Doctors were 3.6 times more likely to have a positive attitude than allied HWs. Similarly, nurses were also 3.61 times more likely than allied HWs to have a positive attitude towards COVID-19 infection and prevention measures (see table 6). Positive differences in attitude were also noted among HWs of various age categories, sex, but these differences were not statistically significant.

Determinants of the practice of COVID-19 preventive measures among HWs in Africa: Table 8 shows a multivariate logistic regression model for determinants of the practice of COVID-19 preventive measures among HWs in Africa. Overall, statistically significant differences in terms of the practice of COVID-19 
preventive measures existed among HWs of the various countries. Algeria had the lowest number of HWs with good practice of COVID-19 infection and prevention measures as compared to Uganda (OR 55.63, $p$ $<0.0001$ ), DRC (OR: 19.72, $p<0.0001)$, Ghana (OR: 6.00, $p=0,009)$ and others $(O R=11.60, p<0.0001)$. Statistically significant differences in the practice of COVID-19 preventive measures also existed among various cadres of HWs in Africa. Both doctors (OR: 8.60, p < 0.0001) and nurses (OR: 4.25, p < 0.003) showed good practice of COVID-19 preventive measures compared to Allied (other) cadres of HWs. Good practice of COVID-19 preventive measures also varied among HWs of different religions, and education levels but these differences were not statistically significant.

Relationships between knowledge, attitude, and practice of COVI-19 infection and prevention among HWs in Africa: Tables 9, 10, and 11 show respectively, the influence of knowledge on HWs' attitude, knowledge on practice, and attitude on HWs practice of COVID-19 infection and prevention measures. Adjustments were made for confounding socio-demographic characteristics. Good knowledge of COVID-19 infection and prevention measures had a statistically significant positive impact on HWs attitude (OR:3.52, p = 0.037). Knowledge also positively impacted HW's practice of COVID-19 prevention measures, but this relationship was not statistically significant (OR: $2.21, p=0.189$ ). Similarly, a good attitude had a highly statistically significant positive relationship with good practice of COVID-19 prevention measures (OR:4.66, $p<0.0001$ ).

\section{Discussion}

This study aimed to describe and establish the determinants of frontline health workers' Knowledge, attitudes, and practices during the COVID-19 first wave in Africa and their related factors. Five hundred and thirty-seven (537) Health workers (HWs) from 26 African countries responded to the survey. The study showed that most HWs had poor Knowledge (73.3\%) about COVID-19 infection and preventive measures. This could be because COVID-19 is a new infectious disease in Africa. This poor knowledge would cause rapid spread of the disease, nosocomial contamination, and exposing the lives of several patients [1]. In addition, this misunderstanding would contribute to the spread of the virus to uninfected patients who seek an assessment $[6,7,12]$. Frontline HWs are directly exposed to SARS-CoV-2 infections. The risk of acquiring COVID-19 is higher among HWs compared to the general population [27]. In addition, this finding highlights the knowledge gap among African HWs and could explain the major barriers to infection control in the African region. Therefore, most HWs had not encountered it in their practice, this agrees with a study done among HWs in Ethiopia on Ebola [27]. However, since Africa has experienced several deadly infectious diseases in the past, most of the HWs demonstrated a good attitude (89\%) and $(90.3 \%)$ practice measures towards preventing COVID-19 infections. This finding agrees with a study conducted in Pakistan which reported a high positive attitude among HWs about COVID-19 [27], but higher than findings reported in Uganda and Ethiopia with $21 \%$ and $35 \%$ respectively $[16,28]$.

Generally, statistically significant determinants of knowledge of COVID-19 infection and prevention measures in the multivariate analysis were HWs' country of work, their cadre, and education level. This 
finding differs from the study by Mulusew Andralem where age less than 34 years, rural residence and access to infection prevention (IP) training were determinants of knowledge of HW towards COVID-19 in Ethiopia [29]. This study revealed that Algeria had the least number of HW with good knowledge about COVID-19 while Uganda had the greatest number of HWs with good knowledge. $(\mathrm{OR}=34.09, \mathrm{p}<0.0001)$ followed by Ghana (OR=13.22, $p<0.0001)$. HWs from DRC were also more knowledgeable on COVID-19 than those from Algeria $(O R=4.59, p=0.015)$. Compared to other cadres of HWs (Allied HWs), doctors were 3.26 times more knowledgeable on COVID-19 infection and preventive measures $(O R=3.26, p=$ 0.005 ) while nurses were $36 \%$ less likely to have good knowledge of COVID-19 infection and prevention measures compared to the allied health caregivers although this difference was not statistically significant $(\mathrm{OR}=0.64, \mathrm{p}=0.383)$. The study also showed that in most countries, doctors were more knowledgeable on COVID-19 compared to other cadres of HWs which showed a similar result with the study by Olum et al [16]. This could be because doctors are always the first to contact patients, which could have prompted them to read more about the novel COVID-19 to better their Knowledge for diagnosis and prevention of the disease. This is consistent with other studies whereby clinical HWs were more knowledgeable on COVID-19 than their non-clinical counterparts [26]. Except for certificate holders, knowledge of COVID-19 infection and prevention measures increase with increasing level of education. This finding agrees with the finding of Kassie and colleagues [30]. Good knowledge about COVID-19 is correlated with having a higher educational status because of increased opportunity to access local and international information, mini-round, seminars, lectures, research, conference, and knowledge. These results are different from other studies which reported that the majority of frontline HWs use social media to seek information about COVID-19 $[16,27,35,36]$.This study showed that $89 \%$ of participants had a positive attitude towards COVID-19. This finding agrees with a study conducted in Pakistan which reported a high positive attitude among HWs about COVID-19 (15). This result is higher than the findings reported in Uganda and Ethiopia in term of $21 \%$ and $65.7 \%$ respectively $[8,14,25,29]$. This finding could be explained by the fact that Africa has experienced several deadly infectious diseases in the past, most of the HWs demonstrated a good attitude $(89 \%)$ and $(90.3 \%)$ practice measures towards preventing COVID-19 infections. This statement is confirmed by a multivariate positive logistic regression found between attitude and practice in this study. The above finding of positive attitude among African frontline HWs is corroborated with the findings of Bhagavathula et al. who revealed that $78 \%$ of HWs, had positive attitude about COVID-19 [26].

Interestingly, the factors positively associated with Attitude of frontline HWs towards COVID-19 in Africa were countries of workplace and cadre of HWs. All study participants from Ghana showed good attitude towards COVID-19 preventive measures. This finding corroborates with previous studies [32-34]. Algeria had the least number of HW with good attitude compared to those from Uganda (OR: 4.58, $p=0.046$ ), DRC (OR: $3.95, p=0.013$ ) and others (OR: 2.57, $p=0.045$ ). The cadre of HWs also had a statistically significant positive influence on attitude towards COVID-19 infection and prevention measures. Doctors were 3.6 times more likely to have a positive attitude than allied HWs. Similarly, nurses were also 3.61 times more likely than allied HWs to have a positive attitude towards COVID-19 infection and prevention measures (see table 6). Positive differences in attitude were also noted among HWs of various age 
categories, sex, but these differences were not statistically significant. These results are similar with other surveys $[15,22]$. The cadre of HWs also had a statistically significant positive influence on attitude towards COVID-19 infection and prevention measures. Doctors were 3.6 times more likely to have a positive attitude than allied HWs. Similarly, nurses were also 3.61 times more likely than allied HWs to have a positive attitude towards COVID-19 infection and prevention measures (see table 6). Positive differences in attitude were also noted among HWs of various age categories, sex, but these differences were not statistically significant.

In addition, the survey found that $90.3 \%$ of participants had good practices regarding COVID-19. This finding has revealed a good practice among African HWs. This result corroborates with previous studies [29]. Overall, statistically significant differences exist among HWs of the various countries in terms of practice of COVID-19 preventive measures. Algeria had the lowest number of HWs with good practice of COVID-19 infection and prevention measures as compared to Uganda (OR 55.63, $p<0.0001$ ), DRC (OR:19.72, $p<0.0001$ ), Ghana (OR: $6.00, p=0,009)$ and others (OR=11.60, $p<0.0001)$. Statistically significant differences in practice of COVID-19 preventive measures also existed among various cadres of HWs in Africa. Both doctors (OR: 8.60, $p<0.0001$ ) and nurses (OR: 4.25, $p<0.003$ ) showed good practice of COVID-19 preventive measures compared to Allied cadres of HWs. Good practice of COVID-19 preventive measures also varied among HWs of different religions, and education levels but these differences were not statistically significant. The results of this could inform policy makers on the practice of African frontline HWs towards SARS-CoV-2 infections. The findings by providing a more precise assessment of the magnitude of good practice among frontline HWs, offer an additional robust knowledge in literature. However, the determinants of practice towards COVID-19 identified in this study differe from those revealed by Mulusew Andualem where rural residence, facility type, access to IP training, presence of IP guidelines, knowledge about COVID-19, having chronic illnesses, lack of protective equipment (PPE), and high workload were factors of COVID-19 prevention [29].

Correlations among Knowledge, attitude and practice of COVID-19 infection measures showed that good Knowledge of COVID-19 infection and prevention measures impacted HWs attitude and practice on COVID-19 preventive measures. Similar findings were also reported in previous studies $[27,29,30]$. This further emphasizes the need to have all HWs handling COVID-19 patients better trained about the disease for better patient health care outcomes and supplied with all the necessary PPEs to ensure that HWs do not get infected with the virus when handling patients [29, 31].

Limitation of the study: This study collected data from 26 countries in Africa. This means that our study findings could be truly representative of the KAP of HWs from across Africa. However, we acknowledge that some countries' responses were fewer than others, which could have affected the study findings. As the area of study was bigger and financial constraint, we didn't find adequate sample size to include in our study which could help us to assess better knowledge, attitude and practices of African frontline HWs. Then, the study assessed knowledge and attitude and practice, it may not necessarily reflect the actual attitude, practice and that people comply with. The best way to assess practice could be by daily 
observation of African frontline HWs. Despite these limitations, our findings provide valuable information about African frontline HWs' KAP regarding COVID-19.

\section{Conclusions}

Majority of the frontline HW in Africa had an overall good attitude and practice towards the COVID-19 infection and prevention measures despite a comparatively poor knowledge about the disease. A good knowledge of COVID-19 infection and prevention measures however, positively impacted HWs attitude and practice on COVID-19 preventive measures. Determinants of knowledge of COVID-19 infection prevention measures among HWs include, country of workplace, cadre and level of education while country of workplace and HWs' cadre were the determinants for both attitude and practice. Promoting inter-state bench-marking and experience sharing among African countries in addition to regular refresher trainings for HWs could help to enhance their KAP towards COVID-19 infection and prevention measures.

\section{List Of Abbreviations}

OR: Odds ratio; Cl: Confidence interval; HW: Health worker; KAP: Knowledge-Attitude-Practice.

\section{Declarations}

Ethics approval, consent to participate and for publication: Before collecting data, Ethical approval has been cleared by the Integrated Multidisciplinary Research Center Ethics committee (IMRCEC) of Adventist University of Lukanga (Campus Wallace, Lukanga, DRCongo). (Protocol Number.02/2020). The study was conducted according to the Declaration of Helsinki and all participants signed a written informed consent. Participants consented for Publication.

Competing interests: Authors declare no competing interests.

Availability of data and materials: The datasets generated during and analyzed during the current study are not publicly available due to legal and ethical reasons but are available from the corresponding author on reasonable request.

Funding Statement: No funding is to be disclosed.

Author contributions: LKK conceived and designed the study and wrote the first draft of the manuscript. LKK, HML, ESB, ZMS, DKM, BMK, SKN, FKS, MMV, LMK, AKK, YALT, BMV, undertook the data collection and coordinated of the activities in different countries; LMK and RNI did the statistical analysis. KS, HML and LKK discussed the findings. LKK, HML, RNI, BMK, AKN, FK, LMK. ESB, FK, TKK did the manuscript correction, critical review of the final manuscript and LKK and SR did the supervision of the work. All authors contributed in intellectual content and approved of the final manuscript. All authors have read and agreed to the final manuscript. 
Acknowledgments: The authors would like to thank all respondents for their voluntary participation and cooperation in this study. LK is grateful to the Uganda government through the Excellence scholarship program under Ministry of Health Sponsorship in the FY 2020/2021 HML and SKN are thankful to the Else-Kröner-Fresenius-Stiftung , Holger-Poehlmann-Stiftung and the NGO Förderverein Uni Kinshasa e.V., fUNIKIN through the Excellence Scholarship Program "Bourse d'Excellence Bringmann aux Universités Congolaises, BEBUC".

\section{References}

1. Rancourt DG. Face masks, lies, damn lies, and public health officials: " A growing body of evidence." 2020;(August).

2. Paterlini M. On the front lines of coronavirus: The Italian response to covid-19. BMJ [Internet]. 2020;368(March):1-2. Available from: http://dx.doi.org/doi:10.1136/bmj.m1065

3. Liu Z, Magal P, Seydi O, Webb G. Understanding unreported cases in the COVID-19 epidemic outbreak in Wuhan, China, and the importance of major public health interventions. Biology (Basel). 2020;9(3).

4. Zhou P, Yang X Lou, Wang XG, Hu B, Zhang L, Zhang W, et al. A pneumonia outbreak associated with a new coronavirus of probable bat origin. Nature. 2020;579(7798):270-3.

5. Ayebare R, Waitt P, Okello S, Kayiira M, Atim Ajok M, Nakatudde I, et al. Leveraging investments in Ebola preparedness for COVID-19 in Sub-Saharan Africa. AAS Open Res. 2020;3(May):3.

6. Sirina Keesara MD, Andrea Jonas MD, Kevin Schulman M. Covid-19 and Health Care's Digital Revolution. N Engl J Med [Internet]. 2020;1-2. Available from: nejm.org

7. Joshi JR. COVSACK: an innovative portable isolated and safe COVID-19 sample collection kiosk with automatic disinfection. Trans Indian Natl Acad Eng [Internet]. 2020;5(2):269-75. Available from: https://doi.org/10.1007/s41403-020-00139-1

8. Nguyen LH, Drew DA, Graham MS, Joshi AD, Guo CG, Ma W, et al. Risk of COVID-19 among frontline health-care workers and the general community: a prospective cohort study. Lancet Public Heal. 2020;5(9):e475-83.

9. Nearly 300,000 Healthcare Workers Have Been Infected With Covid-19 Worldwide, Threatening Health Systems [Internet]. [cited 2021 Oct 22]. Available from: https://www.forbes.com/sites/williamhaseltine/2020/11/17/the-infection-of-hundreds-of-thousands-ofhealthcare-workers-worldwide-poses-a-threat-to-national-health-systems/?sh=1e94b38f3499

10. World Covid-19 tracker: Latest cases and deaths by country [Internet]. [cited 2021 Oct 22]. Available from: https://edition.cnn.com/interactive/2020/health/coronavirus-maps-and-cases/ 
11. Ritchie H, Mathieu E, Rodés-Guirao L, Appel C, Giattino C, Ortiz-Ospina E, et al. Coronavirus Pandemic (COVID-19). Our World Data [Internet]. 2020 Mar 5 [cited 2021 Oct 22]; Available from: https://ourworldindata.org/coronavirus

12. Kimball A, Hatfield KM, Arons M, James A, Taylor J, Spicer K, et al. Asymptomatic and Presymptomatic SARS-CoV-2 Infections in Residents of a Long-Term Care Skilled Nursing Facility - . Morb Mortal Wkly Rep Summ CDC. 2020;69(13):377-81.

13. Kapata N, Ihekweazu C, Ntoumi F, Raji T, Chanda-Kapata P, Mwaba P, et al. Is Africa prepared for tackling the COVID-19 (SARS-CoV-2) epidemic. Lessons from past outbreaks, ongoing pan-African public health efforts, and implications for the future. Int J Infect Dis. 2020;93(February):233-6.

14. Driggin E, Madhavan M V, Bikdeli B, Chuich T, Harm PD. Cardiovascular considerations for patients, health care workers, and health systems during the coronavirus disease 2019 (COVID-19) pandemic. J Am Coll Cardiol. 2020;75(January):2352-71.

15. Al. L et. Since January 2020 Elsevier has created a COVID-19 resource centre with free information in English and Mandarin on the novel coronavirus COVID-. Ann Oncol [Internet]. 2020;(January):19-21. Available from: https://www.ncbi.nlm.nih.gov/pmc/articles/PMC8057862/

16. Olum R, Chekwech G, Wekha G, Nassozi DR, Bongomin F. Coronavirus Disease-2019: Knowledge, Attitude, and Practices of Health Care Workers at Makerere University Teaching Hospitals, Uganda. Front Public Heal. 2020 Apr 30;8.

17. Kassie AD, Bifftu BB, Mekonnen HS. Self-medication practice and associated factors among adult household members in Meket district, Northeast Ethiopia, 2017. BMC Pharmacol Toxicol. 2018 Apr $10 ; 19(1)$.

18. M S, MM M, Su R, A G, S N, Z A, et al. Knowledge, attitude, practice and perceived barriers among healthcare professionals regarding COVID-19: A Cross-sectional survey from Pakistan. J Hosp Infect [Internet]. 2020 Apr 17 [cited 2021 Oct 21]; Available from:

https://europepmc.org/article/PPR/PPR151508

19. Nkansah C, Serwaa D, Adarkwah LA, Osei-Boakye F, Mensah K, Tetteh P, et al. Novel coronavirus disease 2019: Knowledge, practice and preparedness: A survey of healthcare workers in the offinso-north district, Ghana. Pan Afr Med J. 2020;35(Supp 2):1-6.

20. Maina J, Ouma PO, Macharia PM, Alegana VA, Mitto B, Fall IS, et al. A spatial database of health facilities managed by the public health sector in sub Saharan Africa. Sci Data. 2019;6(1):1-8.

21. WHO. Operational Guidance For Maintaining Essential Health Services During An Outbreak. World Heal Organ [Internet]. 2020;(March):1-10. Available from: https://www.who.int/publications-detail/covid19-operational-guidance-for-maintaining-essential-health-services-during-an-outbreak 
22. World Health Organization Regional Office for Africa. Atlas of African Health Statistics 2018: Universal health coverage and the Sustainable Development Goals [Internet]. WHO African Health Observatory and Knowledge Management. 2018. 1-181 p. Available from: http://www.afro.who.int/en/clusters-a-programmes/ard/african-health-observatory-a-knowledgemanagement/features/4008-atlas-of-african-health-statistics-2014-health-situation-analysis-of-theafrican-region.html

23. World Health Organisation. Coronavirus Disease (COVID-19) Situation Reports [Internet]. [cited 2021 Jul 16]. Available from: https://www.who.int/emergencies/diseases/novel-coronavirus2019/situation-reports

24. Zhong BL, Luo W, Li HM, Zhang QQ, Liu XG, Li WT, et al. Knowledge, attitudes, and practices towards COVID-19 among chinese residents during the rapid rise period of the COVID-19 outbreak: A quick online cross-sectional survey. Int J Biol Sci. 2020;16(10):1745-52.

25. Goni MD, Naing NN, Hasan H, Wan-Arfah N, Deris ZZ, Arifin WN, et al. Development and validation of knowledge, attitude and practice questionnaire for prevention of respiratory tract infections among Malaysian Hajj pilgrims. BMC Public Health. 2020;20(1):1-10.

26. Huynh G, Nguyen T, Tran V, Vo K, Vo V, Pham L. Knowledge and attitude toward COVID-19 among healthcare workers at District 2 Hospital, Ho Chi Minh City. Asian Pac J Trop Med. 2020 Jun 1;13(6):2605 .

27. Abebe TB, Bhagavathula AS, Tefera YG, Ahmad A, Khan MU, Belachew SA, et al. Healthcare professionals' awareness, knowledge, attitudes, perceptions and beliefs about Ebola at Gondar University Hospital, Northwest Ethiopia: A cross-sectional study. J Public Health Africa. 2016;7(2).

28. M S, MM M, Su R, A G, S N, Z A, et al. Knowledge, attitude, practice and perceived barriers among healthcare professionals regarding COVID-19: A Cross-sectional survey from Pakistan. J Hosp Infect [Internet]. 2020 Apr 17 [cited 2021 Oct 22]; Available from:

https://europepmc.org/article/PPR/PPR151508

29. Asemahagn MA. Factors determining the knowledge and prevention practice of healthcare workers towards COVID-19 in Amhara region, Ethiopia: a cross-sectional survey. Tropical medicine and health. 2020 Dec;48(1):1-1.

30. Kassie BA, Adane A, Tilahun YT, Kassahun EA, Ayele AS, Belew AK. Knowledge and attitude towards COVID-19 and associated factors among health care providers in Northwest Ethiopia. PloS one. 2020 Aug 28;15(8):e0238415.

31. le Roux C, Dramowski A. Personal protective equipment (PPE) in a pandemic: Approaches to PPE preservation for South African healthcare facilities. South African Med J. 2020;110(6):466-8. 
32. Control CfD, Prevention. Preparing for COVID-19: long-term care facilities, nursing homes. March; 2020.

33. Greenhalgh T, Schmid MB, Czypionka T, Bassler D, Gruer L. Face masks for the public during the covid-19 crisis. Bmj. 2020;369.

34. Bartoszko JJ, Farooqi MAM, Alhazzani W, Loeb M. Medical masks vs N95 respirators for preventing COVID-19 in healthcare workers: A systematic review and meta-analysis of randomized trials. Influenza and other respiratory viruses. 2020.

35. Saqlain M, Munir MM, ur Rehman S, Gulzar A, Naz S, Ahmed Z, et al. Knowledge, attitude, practice and perceived barriers among healthcare professionals regarding COVID-19: A Cross-sectional survey from Pakistan. The Journal of Hospital Infection. 2020

36 Giao H, Han NTN, Van Khanh T, Ngan VK, Van Tam V, Le An P. Knowledge and attitude toward COVID-19 among healthcare workers at District 2 Hospital, Ho Chi Minh City. Asian Pacific J Trop Med. 2020;13:3-5.

37. Nkansah C, Serwaa D, Adarkwah LA, Osei-Boakye F, Mensah K, Tetteh P, et al. Novel coronavirus disease 2019: knowledge, practice and preparedness: a survey of healthcare workers in the Offinso-North District, Ghana. The Pan African Medical Journal. 2020;35(79).

38. Afulani PA, Gyamerah AO, Aborigo R, Nutor J, Malechi H, Laar A, et al. Perceived preparedness to respond to the COVID-19 pandemic: a study with healthcare workers in Ghana. medRxiv. 2020.

39. Essel HB, Tachie-Menson A, Osei M, Yeboah E. Towards the Easing of Restrictions During an Infectious Outbreak: A Cross-Sectional Online Survey to Assess the Knowledge, Misperceptions, Attitudes and Behaviour of Ghanaians on the COVID-19 Pandemic. 2020.

40. Cai H, Tu B, Ma J, Chen L, Fu L, Jiang Y, et al. Psychological Impact and Coping Strategies of Frontline Medical Staff in Hunan Between January and March 2020 During the Outbreak of Coronavirus Disease 2019 (COVID-19) in Hubei, China. Medical science monitor: international medical journal of experimental and clinical research. 2020;26:e924171-1.

41. Galbraith N, Boyda D, McFeeters D, Hassan T. The mental health of doctors during the Covid-19 pandemic. BJPsych bulletin. 2020:1-4.

42. Houghton C, Meskell P, Delaney H, Smalle M, Glenton C, Booth A, et al. Barriers and facilitators to healthcare workers' adherence with infection prevention and control (IPC) guidelines for respiratory infectious diseases: a rapid qualitative evidence synthesis. Cochrane Database of Systematic Reviews. 2020(4).

\section{Tables}


Table 1: Distribution of frontlines COVID-19 HWs by country of workplace.

\begin{tabular}{lcc}
\hline Country & Frequency $(\mathrm{n})$ & Percentage (\%) \\
\hline Algeria & 57 & 11.0 \\
Benin & 14 & 2.7 \\
Burkina Faso & 2 & .4 \\
Burundi & 8 & 1.5 \\
Cameroon & 1 & 0.2 \\
Chad & 1 & 0.2 \\
Congo Brazzaville & 3 & 0.6 \\
DRC & 248 & 48.0 \\
Egypt & 9 & 1.7 \\
Ethiopia & 1 & 0.2 \\
Gabon & 1 & 0.2 \\
Ghana & 37 & 7.2 \\
Guinea & 2 & 0.4 \\
Ivory Coast & 3 & 0.6 \\
Kenya & 10 & 1.9 \\
Libya & 4 & 0.8 \\
Malawi & 1 & 0.2 \\
Mali & 1 & 0.2 \\
Morocco & 2 & 0.4 \\
Niger & 3 & 0.6 \\
Nigeria & 3 & 0.6 \\
Rwanda & 5 & 1.0 \\
Senegal & 25 & 4.8 \\
South Africa & 11 & 2.1 \\
Tanzania & 5 & 1.0 \\
Uganda & 60 & \\
\hline
\end{tabular}

Table 2: Socio-demographic characteristics of frontlines COVID-19 HWs 


\begin{tabular}{ll}
\hline Socio-demographic characteristic & Frequency: $\mathbf{n}(\%)$ \\
\hline Age category & $16(3.1)$ \\
<21 years & $180(34.8)$ \\
21-30 years & $167(32.3)$ \\
31-40 years & $93(18.0)$ \\
$41-50$ years & $47(9.1)$ \\
$51-60$ years & \\
Sex & $289(55.9)$ \\
Male & $228(44.1)$ \\
female & \\
Cadre of HWs & $66(12.8)$ \\
Allied HW (others) & $154(29.8)$ \\
Nurses & $297(57.4)$ \\
Doctors & \\
Education level of HWs & $15(2.9)$ \\
Certificate & $54(10.4)$ \\
Diploma & $333(64.4)$ \\
Degree/Bachelors & $81(15.7)$ \\
Masters & $22(4.3)$ \\
Others & \\
Marital status of HWs & $218(42.2)$ \\
Single & $299(57.8)$ \\
Married & \\
Religion of HWs & $32(15.9)$ \\
Muslim & $16(3.1)$ \\
Christians & $23(4.4)$ \\
Jehovah's witness & \\
Others & \\
\hline & \\
\hline &
\end{tabular}

Table 3: Bivariate analysis showing determinants of Knowledge towards COVID-19 infections \& prevention. $*_{-} p$ value from chi-square analysis. 


\begin{tabular}{|c|c|c|c|}
\hline \multicolumn{4}{|c|}{ Knowledge category } \\
\hline Variables & Poor: n (\%) & Good: n (\%) & p-value* \\
\hline Country of workplace & & & $<0.0001$ \\
\hline Algeria & $53(93.0)$ & $4(7.0)$ & \\
\hline $\mathrm{DRC}$ & $192(77.4)$ & $56(22.6)$ & \\
\hline Uganda & $17(28.3)$ & 46 (71.7) & \\
\hline Ghana & $21(56.8)$ & $16(43.2)$ & \\
\hline Others & 96 (83.5) & 19 (16.5) & \\
\hline Age category & & & 0.216 \\
\hline$<20$ years & 15 (93.8) & $1(6.2)$ & \\
\hline $21-30$ years & $125(69.4)$ & $55(30.6)$ & \\
\hline $31-40$ years & 120 (71.9) & $47(28.1)$ & \\
\hline $41-50$ years & $70(75.3)$ & $23(24.7)$ & \\
\hline $51-60$ years & 37 (78.7) & $10(21.3)$ & \\
\hline Sex category & & & 0.170 \\
\hline Female & $205(70.9)$ & $84(29.1)$ & \\
\hline Male & $174(76.3)$ & 54 (23.7) & \\
\hline Cadre of HW & & & $<0.0001$ \\
\hline Others (Allied HW) & $56(84.8)$ & $10(15.2)$ & \\
\hline Nurses & $141(91.6)$ & $13(8.4)$ & \\
\hline Doctors & $182(61.3)$ & $115(38.7)$ & \\
\hline Education level & & & $<0.0001$ \\
\hline Certificate & 13 (86.7) & $2(13.3)$ & \\
\hline Diploma & 49 (90.7) & $5(9.3)$ & \\
\hline Degree/Graduate & $249(74.8)$ & $84(25.2)$ & \\
\hline Masters & $46(56.8)$ & $35(43.2)$ & \\
\hline Others & $22(64.7)$ & $12(35.3)$ & \\
\hline Marital status & & & 0.811 \\
\hline Single & $161(73.9)$ & $57(26.1)$ & \\
\hline Married & $218(72.9)$ & $81(27.1)$ & \\
\hline Religion of HW & & & 0.195 \\
\hline Muslim & $66(80.5)$ & $16(19.5)$ & \\
\hline Christian & $282(71.2)$ & $114(28.8)$ & \\
\hline Jehovah's witness & $14(87.5)$ & $2(12.5)$ & \\
\hline Others & 17 (73.9) & $6(26.1)$ & \\
\hline
\end{tabular}

Table 4: Multivariate analysis showing determinants of Knowledge for COVID-19 infections \& preventions. ${ }^{b}$ only variables in the bivariate analysis with $p<0.2$ were included. 
Odds for good knowledge

\begin{tabular}{|c|c|c|c|c|}
\hline Variables ${ }^{b}$ & Crude OR & p-value & Adjusted OR & p-value \\
\hline Country & & & & $<0.0001$ \\
\hline Algeria & Reference & - & - & \\
\hline DRC & $3.9(1.3-11.1)$ & 0.012 & $4.59(1.34-15.73)$ & 0.015 \\
\hline Uganda & $33.5(10.5-107.0)$ & $<0.0001$ & $34.09(9.26-125.48)$ & $<0.0001$ \\
\hline Ghana & $10.1(3.0-33.7)$ & $<0.0001$ & $13.22(3.36-52.00)$ & $<0.0001$ \\
\hline Others & $2.6(0.8-8.1)$ & 0.094 & $2.09(0.63-6.89)$ & 0.227 \\
\hline Sex & & & & 0.331 \\
\hline Female & Reference & & - & \\
\hline Male & $1.3(0.89-1.96)$ & 0.170 & $0.78(0.48-1.28)$ & 0.331 \\
\hline Cadre of HW & & & & $<0.0001$ \\
\hline Others & Reference & - & - & \\
\hline Nurses & $0.5(0.21-1.25)$ & 0.140 & $0.64(0.23-1.75)$ & 0.383 \\
\hline Doctors & $3.5(1.74-7.21)$ & 0.001 & $3.26(1.43-7.43)$ & 0.005 \\
\hline Education level & & & & 0.011 \\
\hline Certificate & Reference & & - & \\
\hline Diploma & $0.7(0.12-3.82)$ & 0.046 & $0.17(0.02-1.33)$ & 0.091 \\
\hline Degree/Graduate & $2.2(0.48-9.92)$ & 0.308 & $0.50(0.09-3.68)$ & 0.569 \\
\hline Masters & $4.9(1.05-23.35)$ & 0.044 & $0.99(0.15-6.56)$ & 0.991 \\
\hline Others & $3.5(0.68-18.40)$ & 0.132 & $1.46(0.20-10.74)$ & 0.712 \\
\hline Religion of HWs & & & & 0.885 \\
\hline Muslims & Reference & - & & \\
\hline Christians & $1.7(0.93-3.00)$ & 0.088 & $0.98(0.43-2.22)$ & 0.955 \\
\hline Jehovah's Witnesses & $0.6(0.12-2.86)$ & 0.512 & $0.67(0.122-3.85)$ & 0.668 \\
\hline Others & $1.5(0.49-4.28)$ & 0.495 & $1.48(0.38-5.75)$ & 0.574 \\
\hline
\end{tabular}

Table 5: Bivariate analysis showing determinants of attitude towards COVID-19 infection and prevention. * ${ }^{*}$-value from chi-square analysis. 


\begin{tabular}{|c|c|c|c|}
\hline \multicolumn{4}{|c|}{ Attitude category } \\
\hline Variables & Bad: n (\%) & Good: n (\%) & p-value* \\
\hline Country of workplace & & & $<0.0001$ \\
\hline Algeria & $20(35.1)$ & 37 (64.9) & \\
\hline DRC & $19(7.7)$ & $229(92.3)$ & \\
\hline Uganda & $3(5.0)$ & $57(95.0)$ & \\
\hline Ghana & $0(0)$ & $37(100)$ & \\
\hline Others & $15(13.0)$ & $100(87.0)$ & \\
\hline Age category & & & $<0.0001$ \\
\hline$<20$ years & 7 (43.8) & $9(56.2)$ & \\
\hline $21-30$ years & $14(7.8)$ & $166(92.2)$ & \\
\hline $31-40$ years & $15(9.0)$ & $152(91.0)$ & \\
\hline $41-50$ years & $11(11.8)$ & $82(88.2)$ & \\
\hline $51-60$ years & $7(14.9)$ & $40(85.1)$ & \\
\hline Sex category & & & 0.002 \\
\hline Female & $36(15.8)$ & $192(84.2)$ & \\
\hline Male & $21(7.3)$ & $268(92.7)$ & \\
\hline Cadre of HW & & & 0.004 \\
\hline Others (Allied HW) & 11 (16.7) & 55 (83.3) & \\
\hline Nurses & $25(16.2)$ & $129(83.8)$ & \\
\hline Doctors & $21(7.1)$ & $276(92.9)$ & \\
\hline Education level & & & 0.001 \\
\hline Certificate & $6(40.0)$ & $9(60.0)$ & \\
\hline Diploma & $6(11.1)$ & $48(88.9)$ & \\
\hline Degree/Graduate & $40(12.0)$ & $293(88.0)$ & \\
\hline Masters & $4(4.9)$ & $77(95.1)$ & \\
\hline Others & $1(2.9)$ & 33 997.1) & \\
\hline Marital status & & & 0.784 \\
\hline Single & $25(11.5)$ & 193 (88.5) & \\
\hline Married & $32(10.7)$ & 267 (89.3) & \\
\hline Religion of HW & & & $<0.0001$ \\
\hline Muslim & $19(23.2)$ & $63(76.8)$ & \\
\hline Christian & $29(7.3)$ & 367 (92.7) & \\
\hline Jehovah's witness & $4(25.0)$ & $12(75.0)$ & \\
\hline Others & $5(21.7)$ & $18(78.3)$ & \\
\hline
\end{tabular}

Table 6: Multivariate analysis showing determinants of attitude towards COVID-19 infections \& preventions measures. ${ }^{a}$ All HWs had good attitude towards COVID-19 infection and prevention measures ${ }^{b}$. variables in the bivariate analysis with $p<0.2,{ }^{*} p$ value from binary logistic regression, 
Bivariate Logistic regression

Variables $^{a}$

Country

Algeria

DRC

Uganda

Ghana $^{b}$

Others

Sex

Female

Male

Cadre of HW

Others

Nurses

Doctors

Education level

Certificate

Diploma

Degree/Graduate

Masters

Others

\section{Religion of HWs}

Muslims

Christians

Jehovah's Witnesses

Others

Age (years)

$<21$

21-30

$31-40$

41-50

51-60

Crude OR

$\mathrm{p}$-value

Reference

$6.52(3.18-13.35)$

$10.27(2.85-37.02)$

$3.60(1.67-7.77) \quad 0.001$

Reference

$2.39(1.35-4.23)$

$-$

0.003

Reference

$1.03(0.48-2.24)$

0.937

$2.63(1.20-5.76)$

0.016

Reference

$5.33(1.40-20.31)$

0.014

4.88 (1.65- 14.45)

0.004

$12.83(3.04-54.24)$

0.001

$22.00(2.34-207)$

0.007

Reference

$3.82(2.02-7.22)$

$0.91(0.26-3.13)$

0.875

$1.09(0.36-3.31)$

0.885

Reference

$7.88(2.57-24.18)$

$5.80(1.80-18.70)$

0.003

$4.44(1.24-15.87)$

0.022
Multivariate Logistic regression

Adjusted OR

p-value*

$<0.0001$

$3.95(1.33-11.69)$

$4.58(1.03-20.45)$

$2.57(1.02-6.47)$

0.052

$-$

0.013

0.046

$-$

0.045

0.144

$1.690 .81-3.17$ )

$-$

0.178

0.025

$3.61(1.29-10.12)$

0.015

$3.60(1.36-9.53)$

0.010

0.208

$3.08(0.43-22.01)$

0.263

$1.80(0.32-9.97)$

0.503

$4.74(0.65-34.60)$

0.125

10.17 (0.71 - 146.09)

0.088

0.541

$<0.0001$

$1.38(0.54-3.55)$

0.504

$0.57(0.14-2.31)$

$0.66(0.17-2.54)$

0.426

0.544

0.427

$9.22(3.00-28.50)<0.00013 .35(0.86-13.02)$

0.081

$<0.0001$

$2.41(0.63-9.24)$

0.200

$1.79(0.46-7.04)$

0.403

$1.84(0.44-7.78)$

0.408

Table 7: Bivariate analysis showing determinants of HW's Practice of COVID-19 infections measures. * $p$ values from chi-square analysis. 


\begin{tabular}{|c|c|c|c|}
\hline \multirow{2}{*}{\multicolumn{3}{|c|}{ Country of workplace }} & \multirow{7}{*}{$\begin{array}{l}\mathrm{p} \text {-value* } \\
<0.0001\end{array}$} \\
\hline & & & \\
\hline Algeria & $20(35.1)$ & $37(64.9)$ & \\
\hline DRC & $15(6.0)$ & $233(94.0)$ & \\
\hline Uganda & $1(1.7)$ & $59(98.3)$ & \\
\hline Ghana & $6(16.2)$ & $31(83.8)$ & \\
\hline Others & $8(7.0)$ & $107(93.0)$ & \\
\hline \multicolumn{3}{|l|}{ Age category } & \multirow[t]{6}{*}{0.031} \\
\hline$<20$ years & $5(31.3)$ & $11(68.7)$ & \\
\hline 21-30 years & $18(10.0)$ & $162(90.0)$ & \\
\hline $31-40$ years & $11(6.6)$ & $156(93.4)$ & \\
\hline $41-50$ years & $11(11.8)$ & $82(88.2)$ & \\
\hline $51-60$ years & $5(10.6)$ & $42(89.4)$ & \\
\hline \multicolumn{3}{|l|}{ Sex category } & \multirow[t]{3}{*}{0.075} \\
\hline Female & $28(12.3)$ & $200(87.7)$ & \\
\hline Male & $22(7.6)$ & $267(92.4)$ & \\
\hline \multicolumn{3}{|l|}{ Cadre of HW } & \multirow[t]{4}{*}{$<0.0001$} \\
\hline Others (Allied HW) & $15(22.7)$ & $51(77.3)$ & \\
\hline Nurses & 21 (13.6) & $133(86.4)$ & \\
\hline Doctors & $14(4.7)$ & $283(95.3)$ & \\
\hline \multicolumn{3}{|l|}{ Education level } & \multirow[t]{6}{*}{0.087} \\
\hline Certificate & $3(20.0)$ & $12(80.0)$ & \\
\hline Diploma & $6(11.1)$ & 48 (88.9) & \\
\hline Degree/Graduate & $37(11.1)$ & $296(88.9)$ & \\
\hline Masters & $2(2.5)$ & $79(97.5)$ & \\
\hline Others & $2(5.9)$ & $32(94.1)$ & \\
\hline \multicolumn{3}{|l|}{ Marital status } & \multirow{3}{*}{0.782} \\
\hline Single & $22(10.1)$ & $196(89.9)$ & \\
\hline Married & $28(9.4)$ & $271(90.6)$ & \\
\hline \multicolumn{4}{|l|}{ Religion of HW } \\
\hline Muslim & $16(19.5)$ & $66(80.5)$ & \multirow[t]{4}{*}{0.009} \\
\hline Christian & $30(7.6)$ & $366(92.4)$ & \\
\hline Jehovah's witness & $1(6.3)$ & 15 (93.7) & \\
\hline Others & $3(13.0)$ & $2087.0)$ & \\
\hline
\end{tabular}

Table 8: Multivariate analysis showing determinants of practice towards COVID-19 infections \& preventions. ${ }^{a}$ only variables in the bivariate analysis with $p<0.2$ were included. * p-value from binary logistic regression. 


\begin{tabular}{|c|c|c|c|c|}
\hline \multirow[b]{3}{*}{ Variables $^{a}$} & \multicolumn{4}{|c|}{ Odds for good practice } \\
\hline & \multicolumn{2}{|c|}{ Bivariate Logistic regression } & \multicolumn{2}{|c|}{ Multivariate Logistic regression } \\
\hline & Crude OR & p-value & Adjusted OR & p-value* \\
\hline Country & & & & $<0.0001$ \\
\hline Algeria & Reference & - & & \\
\hline DRC & $8.40(3.95-17.85)$ & $<0.0001$ & $19.72(6.08-63.92)$ & $<0.0001$ \\
\hline Uganda & $31.90(4.11-247.7)$ & $<0.0001$ & $55.63(5.90-524.6)$ & $<0.0001$ \\
\hline Ghana & $2.79(1.00-7.82)$ & 0.001 & $6.00(1.57-23.02)$ & 0.009 \\
\hline Others & $7.23(2.94-17.80)$ & 0.051 & $11.60(3.87-34.74)$ & $<0.0001$ \\
\hline Sex & & & & 0.951 \\
\hline Female & Reference & & & \\
\hline Male & $1.70(0.94-3.06)$ & 0.077 & $0.98(0.473-2.02)$ & 0.951 \\
\hline Cadre of HW & & & & $<0.0001$ \\
\hline Others & Reference & & & \\
\hline Nurses & $1.86(0.86-3.89)$ & 0.098 & $4.25(1.65-10.93)$ & 0.003 \\
\hline Doctors & $5.95(2.71-13.06)$ & $<0.0001$ & $8.60(3.22-23.00)$ & $<0.0001$ \\
\hline Education level & & & & 0.221 \\
\hline Certificate & Reference & - & & \\
\hline Diploma & $2.00(0.44-9.18)$ & 0.373 & $2.60(0.33-20.37)$ & 0.363 \\
\hline Degree/Graduate & $2.00(0.54-7.42)$ & 0.300 & $1.40(0.22-8.90)$ & 0.724 \\
\hline Masters & $9.88(1.49-65.33)$ & 0.018 & $6.42(0.63-65.90)$ & 0.118 \\
\hline Others & $4.00(0.59-26.97)$ & 0.154 & $3.76(0.30-47.04)$ & 0.304 \\
\hline Religion of HWs & & & & 0.633 \\
\hline Muslims & Reference & - & & \\
\hline Christians & $2.96(1.53-5.73)$ & 0.001 & $0.97(0.36-2.64)$ & 0.957 \\
\hline Jehovah's Witnesses & $3.64(0.45-29.60)$ & 0.227 & $2.84(0.27-29.96)$ & 0.386 \\
\hline Others & $1.62(0.43-6.12)$ & 0.480 & $2.25(0.42-12.05)$ & 0.342 \\
\hline Age category (years) & & & & 0.742 \\
\hline$<21$ & Reference & & & \\
\hline $21-30$ & $4.09(1.28-13.10)$ & 0.003 & $0.50(0.11-2.16)$ & 0.350 \\
\hline $31-40$ & $6.45(1.90-21.86)$ & 0.003 & $0.77(0.17-3.54)$ & 0.737 \\
\hline $41-50$ & $3.39(1.00-11.60)$ & 0.052 & $0.46(0.10-2.16)$ & 0.324 \\
\hline $51-60$ & $3.82(0.94-15.58)$ & 0.062 & $0.66(0.12-3.54)$ & 0.624 \\
\hline
\end{tabular}

Table 9: Multi-variate logistic regression showing the influence of HW's knowledge on their attitude towards COVID-19 prevention measures: adjusted for socio-demographic factors. 
Adjusted odds 95\% Confidence interval p-value ratio

(CI)

Lower limit Upper limit
Knowledge

Category

Bad

Good

Age Category

$<20$ years

21-30 years

31-40 years

41-50 years

51-60 years

Sex category

Female

Male

HW category

Others

Nurses

Doctors

Religion

Muslims

Christians

Jehovah's

Witnesses

Others

Country

Algeria

DRC

Uganda

Ghana

Others

Education level

Certificate

Diploma

Degree/Bachelors

Masters

Others
Reference

3.52

Reference

3.67

2.62

1.92

2.01

Reference

1.72

Reference

3.78

3.13

Reference

1.41

0.61

0.66

Reference

3.45

2.31

$-$

2.55

Reference

3.62

1.84

4.59

8.96
1.08

11.45

0.037
0.93

0.68

0.49

0.47

0.86

1.34

1.17

0.55

0.15

0.17

1.16

0.48

-

1.01
14.42

10.13

7.57

8.51

3.44

0.126

0.353

0.345
0.161

0.063 
p-value* Adjusted odds ratio 95\% Confidence interval (CI)

Knowledge category $\quad 0.189 \quad$ Lower limit Upper limit

Bad

Reference

Good

0.189

2.21

0.68

7.24

Age Category

0.766

$<20$ years

Reference

21-30 years

0.373

0.51

0.12

2.24

31-40 years

0.761

0.79

0.17

3.63

41-50 years

0.351

0.48

0.10

2.26

51-60 years

0.680

0.70

013

3.80

Sex category

0.993

Female

Reference

Male

0.993

1.00

0.48

2.10

HW category

$<0.0001$

Others

Reference

Nurses

0.003

4.18

1.62

10.74

Doctors

$<0.000$

7.51

2.77

20.40

Religion of respondent

Muslims

Christians

0.597

Reference

Jehovah's Witnesses

0.997

1.00

0.37

2.72

0.337

3.17

0.30

33.29

$0.325 \quad 2.32$

0.43

12.45

Country

Algeria

$<0.0001$

Reference

DRC

$<0.0001$

18.12

5.78

59.00

Uganda

0.002

36.16

3.61

362.05

Ghana

0.018

5.24

1.33

21.00

Others

Education level

$<0.0001$

11.57

3.87

34.62

Certificate

0.243

Diploma

Reference

Degree/bachelors

0.334

2.77

0.35

21.78

0.725

1.40

0.22

8.92

0.122

6.33

0.61

65.50

Others

0.410

3.00

0.23

37.58

Table 11: Influence of HW's attitude on their practice of COVID-19 infection prevention measures; (adjusted for confounding socio-demographic factors). * $p$-value from binary logistic regression. 
Adjusted odds 95\% Confidence interval p-value* ratio

(CI)

Lower limit Upper limit

Attitude category

Bad

Good

Age Category

$<21$ years

21-30 years

31-40 years

41-50 years

51-60 years

HCW category

Others

Nurses

Doctors

Religion

Muslims

Christians

Jehovah's

Witnesses

Others

Country

Algeria

DRC

Uganda

Ghana

Others

Sex category

Female

Male

Education level

Certificate
Diploma
Degree/bachelors
Masters
Others

Reference

4.66

1.98

Reference

0.33

057

0.36

0.61

Reference

3.78

7.25

Reference

0.85

2.83

2.91

Reference

18.60

44.25

3.86

10.47

Reference

0.90

Reference

2.02

1.09

4.14

2.45

Others
5.10

4.57

0.96

3.35

0.30

0.28

0.45

9.42

19.86

0.010

$<0.0001$
0.162

0.488

0.224

0.586

Figures 


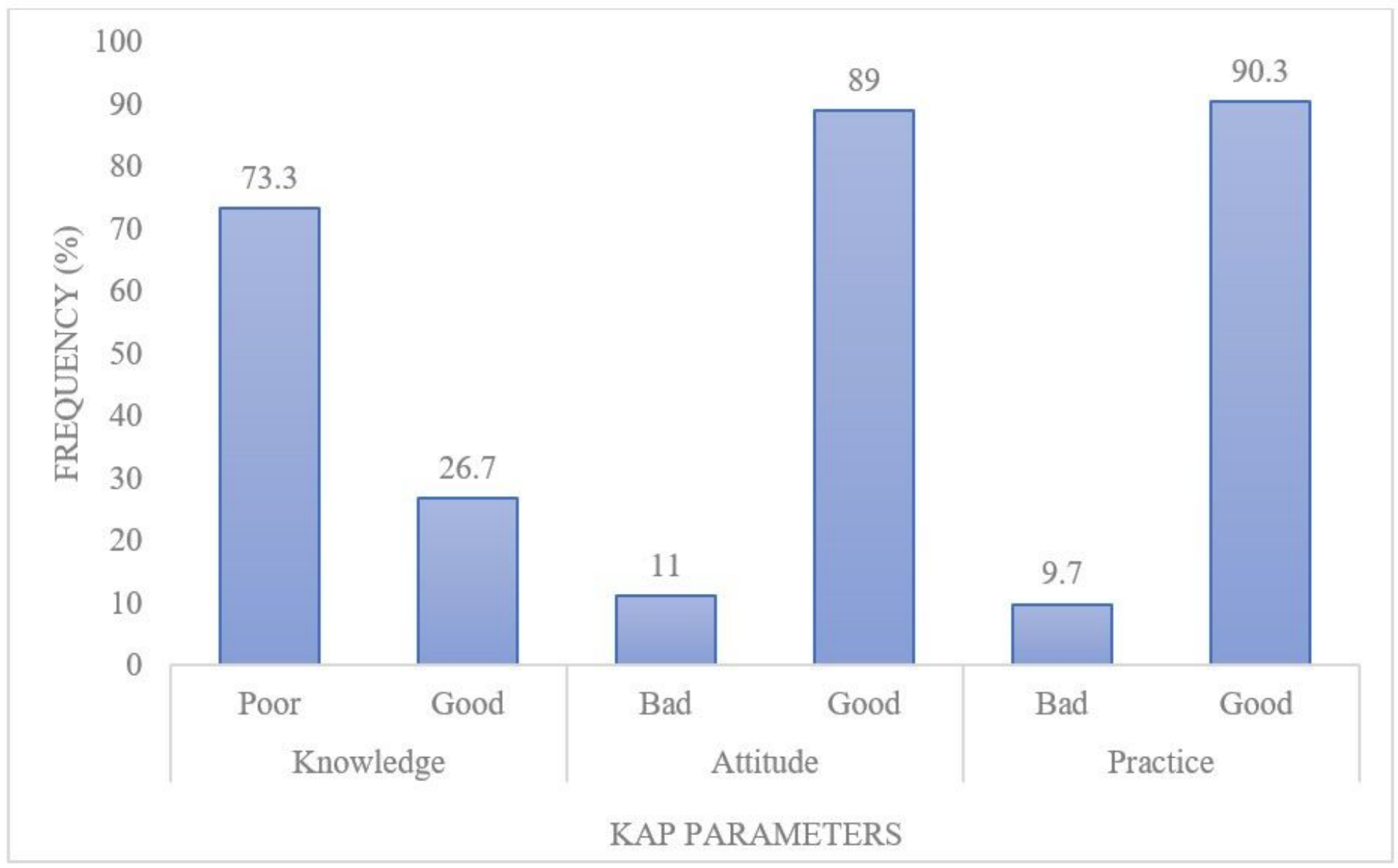

Figure 1

COVID-19 Knowledge, Attitude and Practice distribution among HWs in Africa. 